\title{
Assessment of Relative Water Resources Carrying Capacity and Sustainable Development in Chengdu,China
}

\author{
Zhigang Li \\ College of Management Science \\ Chengdu University of Technology \\ Chengdu, China \\ cdlglzg@163.com
}

\author{
Yangjie Tian \\ College of Earth Science \\ Chengdu University of Technology \\ Chengdu, China \\ TianYangJie_CDUT@163.com
}

\begin{abstract}
Water shortage has become an important factor restricting the sustainable development of cities. This paper adopts the research ideas and methods of relative resource carrying capacity, and uses China's national and Chongqing as reference areas to evaluate the relative water resources carrying capacity, the relative economic resource carrying capacity and the synthetic carrying capacity of Chengdu from 2000 to 2015, and analyzes Chengdu's carrying capacity of water resources relative to population and economy. Using the same method, the resource carrying capacity of each district and county in Chengdu from 2000 to 2015 was evaluated, and the spatial distribution of water resources in various districts and counties was analyzed. The research shows that compared with China's national and Chongqing, the relative water resources carrying capacity of Chengdu has been overloaded for nearly 10 years. To a certain extent, this reflects that Chengdu's economic growth is not compatible with the carrying capacity of water resources, and the existing economic growth model is constantly weakening the capacity of resources. In addition, there are still problems in the imbalance of water resources and economic development in various districts and counties in Chengdu. The water resources carrying capacity in the eastern region has been seriously overloaded, with the central city being in the most severe area, and the water resources in the western region have yet to be further developed and utilized. The research results provide a reference for the grim situation faced by the government in controlling the water resources carrying capacity of Chengdu.Therefore, in order to achieve sustainable development in Chengdu, it is necessary to deal with the coordinated development of population, water resources and social economy.
\end{abstract}

Keywords-relative water resources carrying capacity; relative economic resource carrying capacity; the synthetic carrying capacity ; sustainable development; spatial difference.

\section{INTRODUCTION}

With the rapid development of the economy and the continuous growth of the population, the demand for water resources is also increasing day by day. Various pollutions have also aggravated the shortage of water resources[1,2]. The shortage of water resources will limit the development of cities and even the country. Therefore, the research on the carrying capacity of water resources has attracted the attention of scholars at home and abroad. Foreign scholars generally use a series of indicators to study water resources carrying capacity [3-5]. Chinese scholars have carried out research using different evaluation methods [6]. There are mainly conventional trend method [7], system dynamics method [8], multi-objective decision analysis method [9] and artificial neural network [10]. Each of these methods has its own advantages and disadvantages, but in general there are certain limitations. To this end, domestic scholar Huang Ningsheng [11] combined with the actual situation in China, put forward the relative resource carrying capacity. The relative resource carrying capacity is to compare one or several reference areas as the comparison standard, and compare the resource possession or consumption of the reference area to further calculate the relative resource carrying capacity.

With the rapid development of Chengdu's economy and the increase in population, water resources have become an important factor restricting its development[12]. Based on this, this paper analyzes the dynamic change process of Chengdu's relative resource carrying capacity from 2000 to 2015 with the national and Chongqing as reference areas. The use of GIS to spatial analysis of the number of overloaded people in each district and county relative to Chengdu. These provide a basis for solving the problem of water resources restriction and sustainable development in Chengdu.

\section{STUDY AREA}

Chengdu is located in the western part of the Sichuan Basin, mostly in the plains. In the process of social and economic development in Chengdu, water resources are the most important resource and occupy a basic position in the process of urban economic development and sustainable development. Chengdu belongs to the subtropical warm monsoon climate zone. This climatic condition makes Chengdu's rainfall relatively abundant, with an average annual water resource of more than 30 billion cubic meters. As the capital of Sichuan Province, Chengdu has experienced rapid economic development. According to the 2013 Statistical Yearbook of Chengdu, the gross domestic product (GDP) of Chengdu is RMB 910.889 billion, and the per capita GDP has reached RMB 63,476.59.

\section{MATERIALS AND METHOD}

The research data mainly includes statistical data such as population, total water resources, water resources utilization and GDP in China, Chengdu and Chongqing in the past 16 years (2000-2015). These data are derived from the China Water Resources Bulletin, China Statistical Yearbook, 
Sichuan Water Resources Bulletin, Sichuan Statistical Yearbook, Chongqing Statistical Yearbook and Chongqing

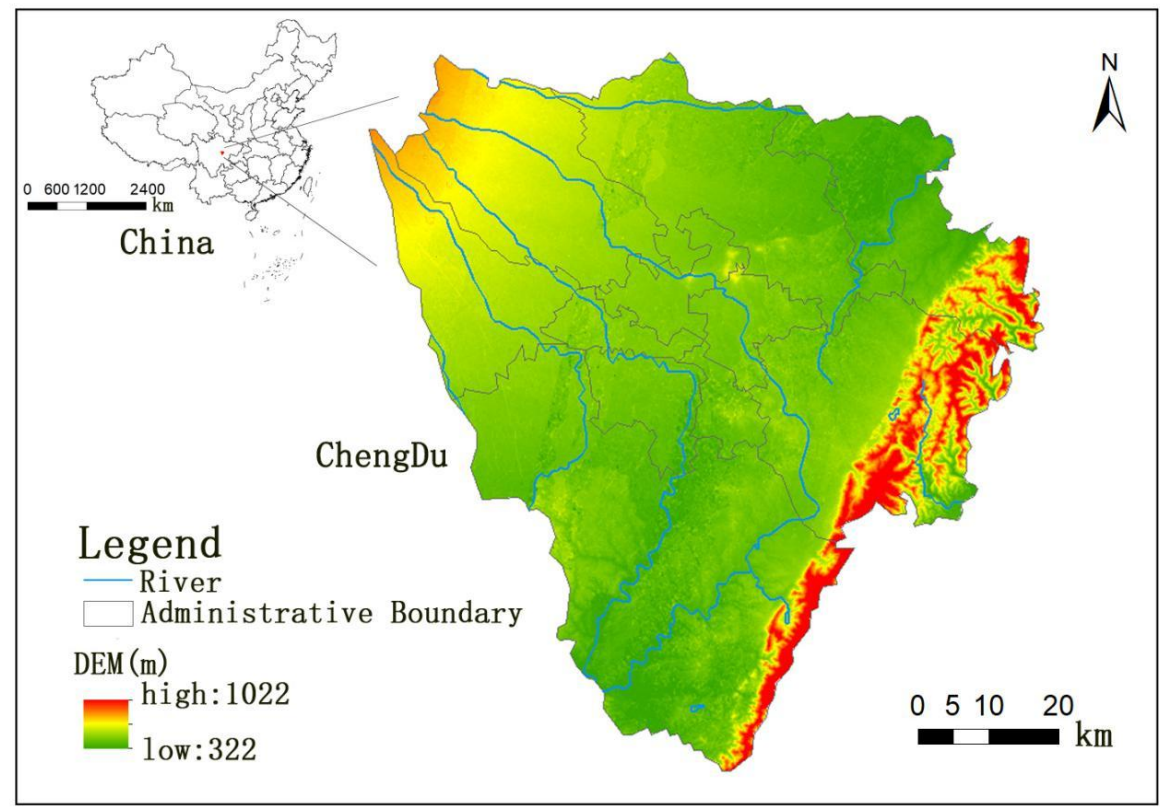

Fig.1 The location of Chengdu

Water Resources Bulletin. The equation calculates the water resources carrying capacity, the economic resource carrying capacity and the synthetic carrying capacity of Chengdu from 2000 to 2015 relative to the whole country and Chongqing, and the average overloaded population of each district and county relative to Chengdu during the period from 2000 to 2015. Then use ArcGIS to realize the spatialization of data and analyze the spatial distribution of water resources in Chengdu.

The synthetic carrying capacity measurement is closely related to water resources, population, and economy. Referring to the existing research, combined with the actual situation of Chengdu, the relative resource carrying capacity calculation equation is as follows[13] :

(1)Relative water resources carrying capacity:

$$
\begin{aligned}
& C_{r w}=I_{w} \bullet Q_{w} \\
& I w=Q_{p o} / Q_{w o}
\end{aligned}
$$

(2)Relative economic resource carrying capacity:

$$
\begin{aligned}
& C_{r e}=I_{e} \bullet Q_{e} \\
& I_{e}=Q_{p o} / Q_{e o}
\end{aligned}
$$

(3)Synthetic carrying capacity :The synthetic carrying capacity is considering the existence of circulation and exchange of resources in the study area[14,15]. It is a regional system with development process and dynamic changes[16,17]. Moreover, water resources are an important resource for human survival and life, and the GDP that can measure the economic development of a region is the gross domestic product. It has a lot to do with the different weights of water resources and economic importance to the population.

$$
C_{s}=W_{w} \bullet C_{r w}+W_{e} \bullet C_{r e}
$$

,Where, $C r w$ was the relative water resources carrying capacity, $I w$ was the reference area water resources carrying capacity index, $Q w$ and $Q w o$ were the total amount of water resources in the study area and reference area, Qpo was the total population of the reference area; Cre was the relative economic resource carrying capacity, Ie was the economic resource carrying capacity index; $Q e$ was the gross domestic product (GDP) of the study area; Qeo was the gross domestic product (GDP) of the reference area; $C s$ was the synthetic carrying capacity of the study area; $W w$ and $W e$ were the weights of relative water resources carrying capacity and relative economic resource carrying capacity, respectively.

Considering the status quo of natural resources and economic development in Chengdu, water resources are relatively short due to the urbanization process[18,19]. Therefore, the relative natural resource carrying capacity weight value should be greater than 0.5 , and the relative economic resource carrying capacity weight value will be correspondingly less than the mean value of 0.5 , the calculated synthetic carrying capacity is more in line with the reality of Chengdu. To this end, assume $\mathrm{Wn}=0.6$ and $\mathrm{We}=0.4$.

(4)Relative resource carrying capacity status evaluation criteria:

By comparing the actual population with its relative resource carrying capacity, the carrying capacity of the study area relative to the reference area in different time periods can be obtained. There are three types[20,21] :

Relative overload status: The actual population $(\mathrm{P})$ is greater than the number of people that can be carried $(\mathrm{Cs})$, i.e. $\mathrm{P}$ - $\mathrm{Cs}>0$.

Relative surplus state: The actual population $(\mathrm{P})$ is less than the number of people that can be carried (Cs), i.e. $\mathrm{P}$ Cs $<0$. 
Relative saturation state: The actual population $(\mathrm{P})$ is equal to the number of people that can be carried (Cs), i.e. $\mathrm{P}$ - $\mathrm{Cs}=0$.

\section{RESULT AND ANALYSIS}

(1)Relative water resources carrying capacity evolution process

\section{A. Taking the country as a reference area}

According to equations (1)-(5), the whole country is selected as the reference area, and the carrying index is calculated from 2000-2015 . It can be seen from Table 1 that the relative population of Chengdu has been overloaded from 2000 to 2015, and the number of overloaded people has increased first and then decreased, and peaked in 2007. From Fig.2, The contribution rate of relative water resources carrying capacity to synthetic carrying capacity has been far less than the relative economic resource carrying capacity and has little change, indicating that the utilization efficiency of water resources in Chengdu has been in a low state in recent years, and the utilization efficiency has not changed much.

\section{B.Taking Chongqing as a reference area}

It can be seen from Table 2 that during 2000-2015, the relative water resources carrying capacity has been lower than the actual population and is in an overloaded state; the relative economic resource carrying capacity has been in a surplus state and continues to rise. In addition to 2001, the synthetic carrying capacity is overloaded; the contribution rate of relative water resources carrying capacity to synthetic carrying capacity has been less than that of relative economic resources.

It can be seen from Fig. 3 that compared with the national comparison or Chongqing, the relative water resources carrying capacity of Chengdu has been overloaded. This result shows that if the economic development speed and scale of the country or Chongqing are used, Chengdu's water resources cannot meet its economic development needs.

(2)Spatial difference of resource carrying capacity in various districts and counties of Chengdu

Taking Chengdu as a reference area, the data of population, GDP, and total water resources of Chengdu and various urban counties from 2000 to 2015 are respectively introduced into equations (1) to (5). The average overloaded number of urban and rural areas relative to Chengdu is obtained, and the spatial distribution map of Chengdu's resource carrying capacity is obtained by using ArcGIS software (Fig. 4). It can be seen from Fig.4 that the number of overloaded people in Chengdu is positive or negative, and the state of resource carrying capacity is judged according to the evaluation criteria. The population of southeastern Chengdu is overloaded relative to water resources, indicating that water resources in the southeast cannot carry the population of the region. Among them, the central city is

TABLE 1 . The status of resource carrying capacity of Chengdu relative to the whole country from 2000 to 2015

\begin{tabular}{|c|c|c|c|c|c|c|c|c|}
\hline Year & $\begin{array}{l}\text { Population } \\
\qquad\left(10^{4}\right)\end{array}$ & $\begin{array}{c}\text { Total water } \\
\text { resources } \\
\left(10^{8} \mathrm{~m}^{3)}\right.\end{array}$ & $\begin{array}{l}\text { GDP } \\
\left(10^{8}\right)\end{array}$ & $\begin{array}{l}\text { Crw } \\
\left(10^{4}\right)\end{array}$ & $\begin{array}{c}\text { Cre } \\
\left(10^{4}\right)\end{array}$ & $\begin{array}{c}\text { Cs } \\
\left(10^{4}\right)\end{array}$ & $\begin{array}{l}\text { Carying } \\
\text { status } \\
\left(10^{4}\right)\end{array}$ & $\begin{array}{l}\text { Contribution } \\
\text { rate }(\%)\end{array}$ \\
\hline 2000 & 1013.35 & 62.16 & 1310.00 & 113.76 & 1655.70 & 730.54 & 282.81 & 15.57 \\
\hline 2001 & 1019.90 & 72.71 & 1492.04 & 138.15 & 1717.66 & 769.95 & 249.95 & 17.94 \\
\hline 2002 & 1028.48 & 64.65 & 1667.10 & 117.56 & 1759.35 & 774.28 & 254.20 & 15.18 \\
\hline 2003 & 1044.31 & 66.62 & 1870.80 & 125.41 & 1759.24 & 778.94 & 265.37 & 16.10 \\
\hline 2004 & 1059.69 & 72.39 & 2185.73 & 155.99 & 1755.55 & 795.81 & 263.88 & 19.60 \\
\hline 2005 & 1082.03 & 76.27 & 2370.76 & 142.20 & 1654.88 & 747.27 & 334.76 & 19.03 \\
\hline 2006 & 1103.40 & 61.02 & 2750.48 & 126.66 & 1647.59 & 735.03 & 368.37 & 17.23 \\
\hline 2007 & 1112.28 & 66.99 & 3324.17 & 140.19 & 1625.34 & 734.25 & 378.03 & 19.09 \\
\hline 2008 & 1124.96 & 90.41 & 3900.99 & 175.06 & 1621.39 & 753.59 & 371.37 & 23.23 \\
\hline 2009 & 1139.63 & 63.44 & 4503.00 & 140.05 & 1721.45 & 772.61 & 367.02 & 18.13 \\
\hline 2010 & 1149.07 & 98.35 & 5551.30 & 170.68 & 1802.24 & 823.30 & 325.77 & 20.73 \\
\hline 2011 & 1163.28 & 104.68 & 6854.58 & 242.58 & 1887.49 & 900.54 & 262.74 & 26.94 \\
\hline 2012 & 1173.30 & 82.01 & 8138.90 & 150.43 & 2039.43 & 906.03 & 267.27 & 16.60 \\
\hline 2013 & 1187.99 & 101.57 & 9108.89 & 197.74 & 2082.28 & 951.56 & 236.43 & 20.78 \\
\hline 2014 & 1210.74 & 75.65 & 10056.59 & 151.80 & 2136.05 & 945.50 & 265.24 & 16.05 \\
\hline 2015 & 1228.05 & 66.32 & 10801.16 & 130.41 & 2154.77 & 940.15 & 287.90 & 13.87 \\
\hline
\end{tabular}




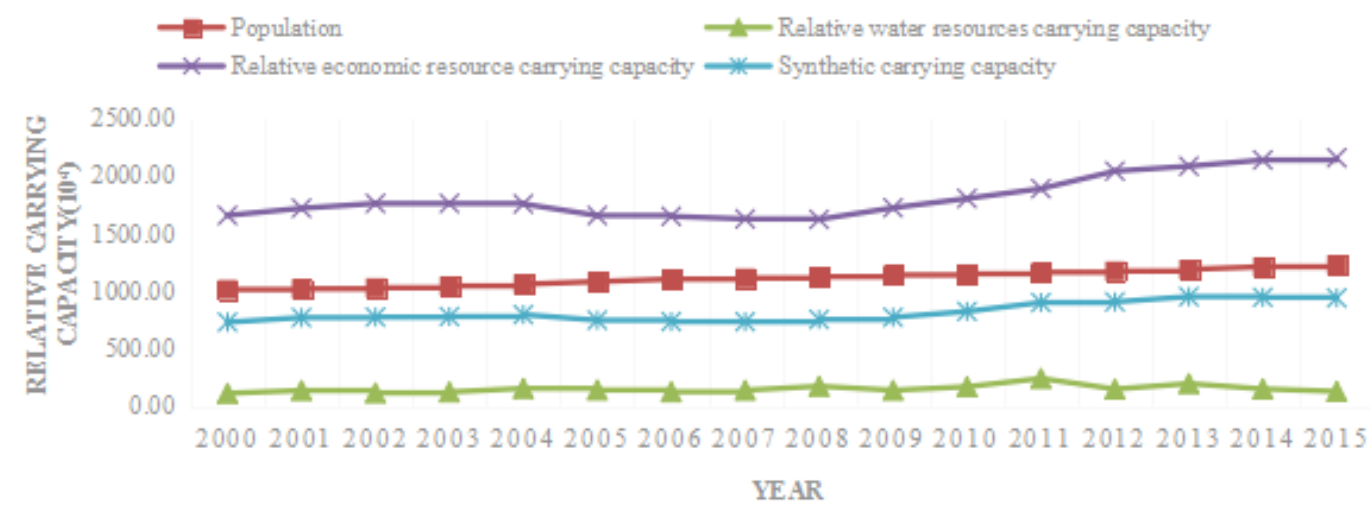

Fig.2 The status of resource carrying capacity of Chengdu relative to the whole country from 2000 to 2015

TABLE 2 . The status of resource carrying capacity of Chengdu relative to Chongqing from 2000 to 2015

\begin{tabular}{|c|c|c|c|c|c|c|c|c|}
\hline Year & $\begin{array}{c}\text { Population } \\
\left(10^{4}\right)\end{array}$ & $\begin{array}{c}\text { Total water } \\
\text { resources } \\
\left(10^{8} \mathrm{~m}^{3)}\right.\end{array}$ & $\begin{array}{c}\text { GDP } \\
\left(10^{8}\right)\end{array}$ & $\begin{array}{c}\text { Crw } \\
\left(10^{4}\right)\end{array}$ & $\begin{array}{c}\text { Cre } \\
\left(10^{4}\right)\end{array}$ & $\begin{array}{c}\text { Cs } \\
\left(10^{4}\right)\end{array}$ & $\begin{array}{c}\text { Carying } \\
\text { status } \\
\left(10^{4}\right)\end{array}$ & $\begin{array}{c}\text { Contribution } \\
\text { rate(\%) }\end{array}$ \\
\hline 2000 & 1013.35 & 62.16 & 1310.00 & 128.58 & 2260.93 & 981.52 & 31.83 & 13.10 \\
\hline 2001 & 1019.90 & 72.71 & 1492.04 & 270.98 & 2338.16 & 1097.85 & -77.95 & 24.68 \\
\hline 2002 & 1028.48 & 64.65 & 1667.10 & 147.52 & 2324.85 & 1018.45 & 10.03 & 14.48 \\
\hline 2003 & 1044.31 & 66.62 & 1870.80 & 141.20 & 2291.25 & 1001.22 & 43.09 & 14.10 \\
\hline 2004 & 1059.69 & 72.39 & 2185.73 & 162.94 & 2264.71 & 1003.65 & 56.04 & 16.23 \\
\hline 2005 & 1082.03 & 76.27 & 2370.76 & 189.66 & 2166.74 & 980.49 & 101.54 & 19.34 \\
\hline 2006 & 1103.40 & 61.02 & 2750.48 & 205.30 & 2251.83 & 1023.91 & 79.49 & 20.05 \\
\hline 2007 & 1112.28 & 66.99 & 3324.17 & 130.77 & 2299.93 & 998.43 & 113.85 & 13.10 \\
\hline 2008 & 1124.96 & 90.41 & 3900.99 & 204.17 & 2193.04 & 999.72 & 125.24 & 20.42 \\
\hline 2009 & 1139.63 & 63.44 & 4503.00 & 182.32 & 2258.81 & 1012.92 & 126.71 & 18.00 \\
\hline 2010 & 1149.07 & 98.35 & 5551.30 & 279.86 & 2313.51 & 1093.32 & 55.75 & 25.60 \\
\hline 2011 & 1163.28 & 104.68 & 6854.58 & 270.95 & 2279.85 & 1074.51 & 88.77 & 25.22 \\
\hline 2012 & 1173.30 & 82.01 & 8138.90 & 229.99 & 2385.00 & 1091.99 & 81.31 & 25.06 \\
\hline 2013 & 1187.99 & 101.57 & 9108.89 & 287.65 & 2393.09 & 1129.83 & 58.16 & 25.46 \\
\hline 2014 & 1210.74 & 75.65 & 10056.59 & 158.94 & 2379.86 & 1047.31 & 163.43 & 15.18 \\
\hline 2015 & 1228.05 & 66.32 & 10801.16 & 196.07 & 2317.18 & 1044.51 & 183.54 & 18.77 \\
\hline & & & & & & & & \\
\hline
\end{tabular}

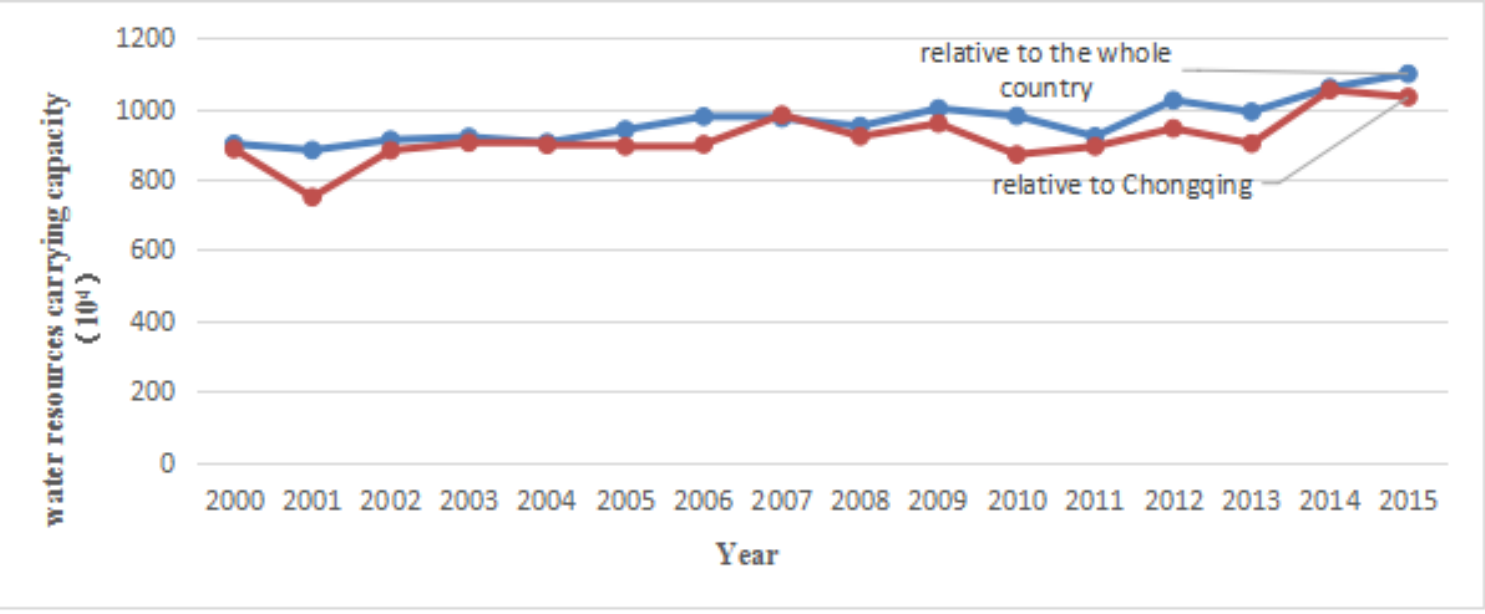

Fig.3 The relative water resources carrying capacity state curve of Chengdu 

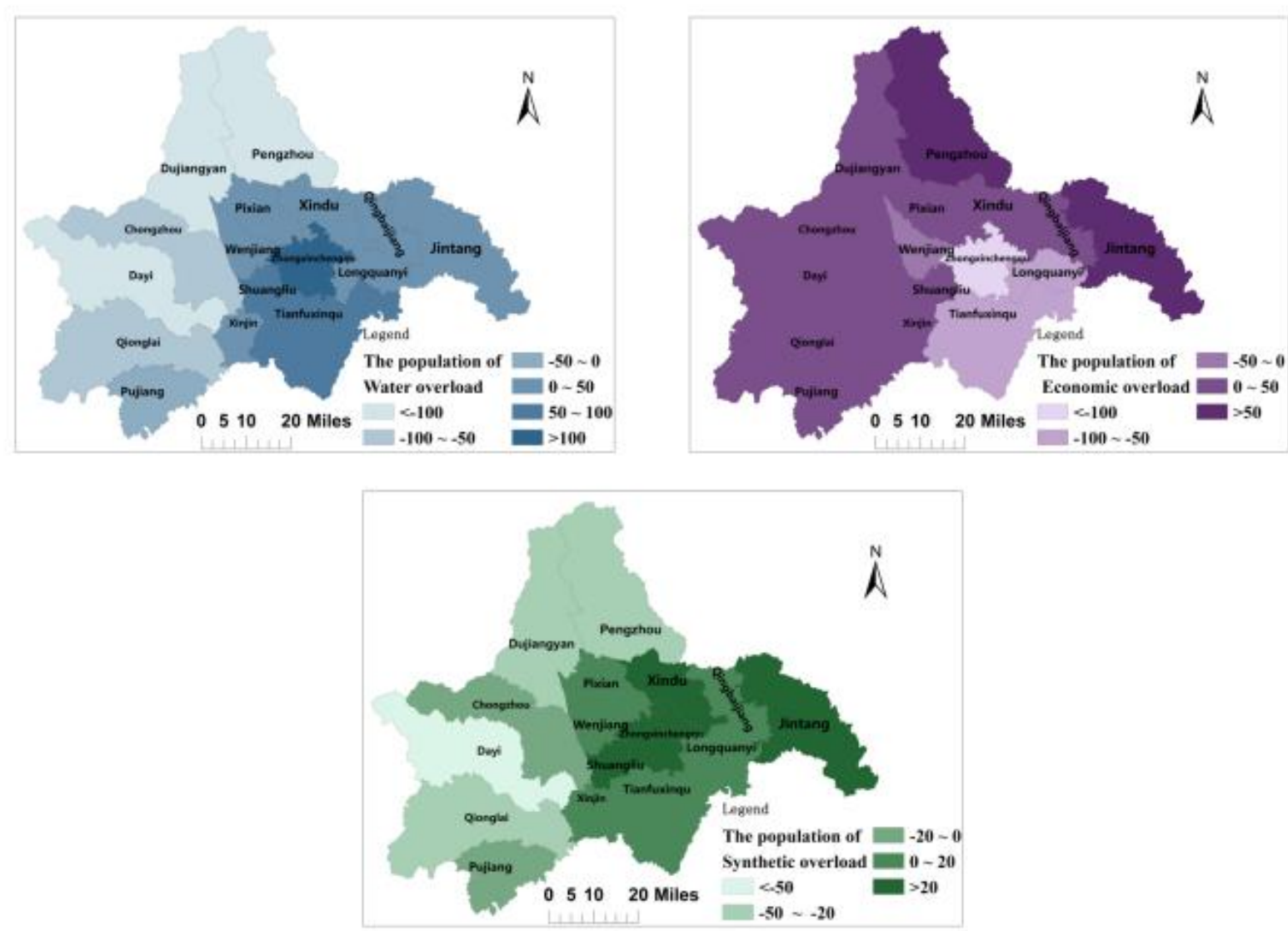

Fig. 4 Spatial distribution map of relative resource carrying capacity of various districts and counties in Chengdu from 2000 to 2015

the most overloaded, indicating that the population of the area needs to be further strictly controlled.

\section{CONCLUSION AND DISCUSSION}

Relative resource carrying capacity involves three aspects: population, water resources and economic development. To achieve sustainable urban development, we need to deal with the coordinated development of population, water resources and social economy. Therefore, from the perspective of Chengdu's relative water resources carrying capacity and synthetic carrying capacity, the following suggestions are proposed:

(1) Compared with the whole country and Chongqing, the water resources carrying capacity of Chengdu has been overloaded; the carrying capacity of economic resources has shown a large upward trend, and it is always in a surplus state; the synthetic carrying capacity is also basically overloaded. To a certain extent, this reflects that the growth of Chengdu's relative economic resource carrying capacity is based on the reduction of relative water resources carrying capacity, and economic growth is not compatible with the supporting capacity of resources. There are three main reasons for this situation: First, water resources are decreasing and resource utilization efficiency is low. Second, the population base is too large and continues to increase, and the amount of water resources per capita is constantly decreasing, which has exerted tremendous pressure on Chengdu's resource carrying capacity. Third, Chengdu's economic growth model is also a reason for the decline of resource carrying capacity. How to make the economy develop at a faster rate with the lowest resource cost and the lowest environmental cost is the key to sustainable development in Chengdu.

(2) From the comparison of the relative resource carrying capacity of various districts and counties in Chengdu from 2000 to 2015, it can be seen that there is an imbalance between the water resources stock and economic development in various districts and counties in Chengdu. The water resources carrying capacity in the eastern region has been seriously overloaded, with the central city being in the most severe area, and the water resources in the western region have yet to be further developed and utilized. At the same time, the carrying capacity of economic resources is overloaded in the western and northeastern regions, while the central urban areas in the central region have the largest surplus. Combined with the synthetic carrying capacity, the eastern part of Chengdu is overloaded, indicating that the eastern natural resources are consumed more, the economic development consumes a lot of water resources, and the water resources stock can no longer support the existing economic growth model. Therefore, different measures should be taken according to the actual conditions of each district and county to implement the resource protection policy while developing the economy. In the western region, we will strengthen the unified management of water resources, combine production and domestic water, agricultural and industrial water, and achieve sustainable recycling of water resources and improve water use efficiency through industrial restructuring and water optimization. In the eastern region, it is necessary to 
strengthen the protection of the environment and natural resources, and to control the structural and spatial patterns of regional water resources utilization. In addition to the amount of water resources in the development area, it is also possible to appropriately increase the utilization of transit water and externally introduce water sources to relieve pressure. Effective and rational use of water resources will enable the balanced development of resources and economy among the districts and counties within Chengdu.

\section{ACKNOWLEDGMENT}

This work was supported by the National Social Science Fund of China:"Ecological Importance and Supporting Policies of Ecological Functional Areas in Key UrbanClusters in China"[No. 19FJY003] and the Landscape and Recreation Research Center Key Project of Sichuan,China[No. JGYQ2019012].

\section{REFERENCES}

[1] Fei, W. , De-Gang, Y. , Chang-Jian, W. , Wen-Jin, X. , \& Fan, Y, "Spatio-temporal characteristics of sustainable development in Xinjiang based on improved relative carrying capacity of resources," Journal of Desert Research, vol. 33, issue 5, pp. 16051613, 2013.

[2] Wang, Liang, and H. Liu. "Comprehensive evaluation of regional resources and environmental carrying capacity using a PS-DR-DP theoretical model," Journal of Geographical Sciences,vol. 29, issue 3, pp. 363-376, 2019.

[3] Joardar S D, "Carrying capacities and standards as bases towards urban infrastructure planning in India : A case of urban water supply and sanitation," Habitat International, vol. 22,issue 3, pp. 327-337, 1998.

[4] Harris J M, Kennedy S. "Carrying capacity in agriculture: global and regional issues," Ecological Economics,vol. 29, issue 3, pp. 443461,1999 .

[5] Rijsberman M A , Ven F H M V D . "Different approaches to assessment of design and management of sustainable urban water systems," Environmental Impact Assessment Review, vol. 20, issue 3, pp. 333-345, 2000.

[6] Jia Z, Cai Y, Chen Y, "Regionalization of water environmental carrying capacity for supporting the sustainable water resources management and development in China," Resources, Conservation and Recycling, vol. 134, pp.282-293, 2018.

[7] Bagheri H, Hajian A , Rezaei M , "Composite of $\mathrm{Cu}$ metal nanoparticles-multiwall carbon nanotubes-reduced graphene oxide as a novel and high performance platform of the electrochemical sensor for simultaneous determination of nitrite and nitrate," Journal of Hazardous Materials, vol. 324, pp. 762-772, 2016.

[8] Zuo Q, "Review of research methods of water resources carrying capacity," Advances in Science \& Technology of Water Resources, vol. 37, issue 3, pp. 1-6 and 54, 2017.

[9] Zhijian H , Jiadi L I , Bin Z , "Evaluation of Capacity of Water Resources in Qinzhou City Based on Multi-objective Decision Analysis". Pearl River, vol. 39, issue 12, pp. 124-128, 2018.

[10] Hui-Qin M , "Evaluation of Ningxia Water Resources Carrying Capacity Based on Artificial Neural Network Method". Ningxia Journal of Agriculture and Forestry Science and Technology, vol. 55, issue 12, pp. 65-68, 2014

[11] Huang Ningsheng, Yan Yaoqiu, "Guangdong's relative resource carrying capacity and sustainable development," Economic Geography, vol. 2000, issue 2, pp. 52-56, 2000 .黄宁生, 匡耀求. “广东相对资源承载力与可持续发展问题, ” 经济地理, vol. 2000 , issue 2, pp. 52-56, 2000 .

[12] Liu, B., Xiao, T., Wang, C., \& Chen, D, "Analyses on Water Vapor Resource in Chengdu City," Agu Fall Meeting, 2017.

[13] Wang Q, Tang H , Li J , "Spatial and Dynamic Analysis of Regional Sustainable Development Using Geographic Information System and Relative Carrying Capacity of Resources". Natural Resources, vol. 2, issue1, pp. 7, 2011.

[14] Changjian, W. , Hongru, D. U. , Xiaolei, Z. , Fei, W. , Li, Z. , \& Xuemei, L. I., "Analysis of relative carrying capacity of resources in Tarim River Basin in Xinjiang." Acta Ecologica Sinica, 2015.

[15] Xiao-Geng, Niu . "Dynamic Empirical Analysis of Relative Water Resources Carrying Capacity of Hebei Province," China Population, Resources and Environment, 2010.

[16] Jia, Huan Huan, and G. M. Yu. "Assessing the Carrying Capacity of Water Resources in Wuhan City, China," Advanced Materials Research, vol. 905, issue1, pp. 5, 2014.

[17] An, Yiwei,. "Relative Carrying Capacity of Resources inYanchi County of Ningxia," Journal of Desert Research , 2017.

[18] Zhichun, Xue, Y. Jinjun , and Y. Zhaohui . "The Chengdu Carrying Capacity of Water Resources Status Evaluation Based on the Variable Sets," IOP Conference Series: Earth and Environmental Science vol.199, issue2018, 2018.

[19] Xiaoni, Xue , "Study on water resources and water environmental carrying capacities of Chengdu," Water Resources and Hydropower Engineering, 2012.

[20] Ait-Aoudia, Meriem Naimi , and E. Berezowska-Azzag . "Water resources carrying capacity assessment: The case of Algeria's capital city," Habitat International vol.58, issue 2016, pp. 51-58,2016.

[21] Yu, Yuan Jun , and L. Wu . "Dynamic Changes of Relative Carrying Capacity of Resources in Dongting Lake," Advanced Materials Research ,vol. 945-949, pp. 3502-3505, 2014. 